\title{
Smartphone dalam Konstruk Teori Ikhlas Beribadah di Era Revolusi Industri 4.0
}

\author{
Lutfiyah \\ UIN Walisongo, Semarang, Indonesia \\ lutfiyah@walisongo.ac.id
}

\begin{abstract}
Abstrak
Era digital, smartphone melahirkan kultur baru bagi penggunanya. Kabar benar dan hoax hilir mudik di media sosial. Perilaku beragama antara hamba dengan Tuhannya yang semestinya sirri dan tidak menjadi urusan privat dengan bukti terdisplaynya ibadah ritual di media sosial. Ibadah semestinya dilakukan dengan khusu' dan bersifat pribadi, mulai ditampilkan melalui smartphone dan dapat dikonsumsi masyarakat secara umum. Tujuan penelitian untuk mengetahui fungsi smartphone jika dibenturkan dengan teori ikhlas beribadah pada era Revolusi Industri 4.0. Tulisan ini menggunakan teknik wawancara tertutup dengan lembar quesioner, dan dokumentasi untuk mengungkapkan bagaimana teori ibadah seharusnya dilaksanakan, teori ikhlas yang sudah didefinisikan oleh para ulama salaf dan bagaimanya penterjemahan orang Muslim di era digital. Subyek dari tulisan ini adalah dosen Pendidikan Agama Islam (PAI) di Universitas Islam Negeri (UIN) Walisongo Semarang. Hasil dari tulisan ini menunjukkan bahwa dosen PAI aktif menggunakan smartphone, tapi tidak memperhatikan konten posting ibadah mahdhah dengan bukti lebih banyak yang abstain.
\end{abstract}

Kata kunci: Ibadah, ikhlas, revolusi industri, smartphone. 


\begin{abstract}
Digital era, smartphone gives birth to a new culture for its users. The news is true and the hoax is going back and forth on social media. The religious behavior between the servant and his Lord should be private and not become a private matter with evidence of the display of ritual worship on social media. Worship should be performed specifically and privately, starting to be displayed through a smartphone and can be consumed by the general public. The purpose of this research is to determine the function of a smartphone when it is clashed with the theory of sincere worship during the Industrial Revolution 4.0 era. This paper uses a closed interview technique with a questionnaire, and documentation to reveal how the theory of worship should be carried out, the sincere theory that has been defined by the salaf scholars and how the translation of Muslims in the digital age. The subject of this paper is a lecturer in Islamic Education (PAI) at the Walisongo State Islamic University (UIN) Semarang. The results of this paper indicate that PAI lecturers actively use smartphones, but do not pay attention to the content of the post ofworship mahdhah with more evidence of abstention.
\end{abstract}

Keywords: Industrial Revolution, sincerity, smartphone, sincere, worship.

\title{
Pendahuluan
}

Smartphone sudah bukan barang baru bagi semua masyarakat Indonesia, karena hampir seluruh lapisan memilikinya. Fungsinya bisa bermacam-macam tergantung dari siapa penggunanya. Bagi peneliti IT, smartphone bisa di "utak atik" dibuat program uji coba yang bisa digunakan dan dimanfaatkan oleh dan untuk orang lain. Rasa puas dan bahagia akan dirasakan oleh programer jika programnya sukses, bukan produk program error. Bagi pengguna (konsumen) biasa, smartphone bisa berguna untuk menyambung silaturrakhim, mendekatkan hubungan jarak jauh sehingga hubungan bisa terjalin kembali dan lebih irit biaya. Bagi penggila smartphone yang sering update status dan posting foto aktifitas pribadi, bisa mengupload setiap saat. Kegiatan selfi, kirim gambar kegiatan pribadi sudah menjamah seluruh sendi kehidupan, bahkan ibadahpun sering diupload sekedar memberitahukan aktifitas beribadah yang sedang dilakukan. Foto di Makkah, di depan ka'bah, foto sedang ceramah, mengisi pengajian sudah tidak malumalu lagi dipasang sebagai profile foto.

Smartphone merupakan kebutuhan tingkat tinggi bagi semua lapisan masyarakat dan sebagai penunjang aktivitas setiap pekerjaan maupun hanya sekedar sebagai lifestyle atau gaya hidup. Kemampuan canggihnya sudah dimanfaatkan oleh masyarakat dalam berbagai lini. Dalam urusan sosial aatau publik seperti perdagangan, perkantoran, 
pendidikan dan kegiatan apapun yang membutuhkan poster, smartphone menjawabnya dengan cepat. Bagi satu konsumen Smartphone merupakan alat yang bekerja menggunakan seluruh perangkat lunak dengan sistem operasi yang menyediakan hubungan standar dan mendasar bagi pengembang aplikasi. Bagi konsumen lainnya telepon cerdas merupakan sebuah telepon yang menyajikan fitur canggih seperti email, internet dan kemampuan membaca buku elektronik (e-book), terdapat papan ketik dan penyambung VGA. Dengan kata lain, telepon cerdas merupakan komputer kecil yang mempunyai kemampuan sebuah telepon (Jocom, 2013).

Smartphone dapat digunakan untuk mengirim pesan gambar yang fungsinya memberitahukan kepada orang, sehingga orang akan paham terhadap kegiatan yang sedang dilakukan. Tanpa kata-kata pesan gambar sudah bisa menjelaskan apa yang sedang dilakukan oleh pengirim gambar. Smartphone juga mampu menyelubungi kehidupan privat masyarakat dengan bukti banyaknya update status yang selalu silih berganti. Facebook, instagram, profile foto WhattApp sering berganti menyesuaikan situasi pemilik smarhphone dan akan diketahui oleh orang yang mengulik akunnya. Rutinitas kegiatan apapun diabadikan sebagi moment penting. Contoh paling ringan adalah WhatsApp Grup (WAG) yang setiap hari silih berganti berisi posting dari anggota WAG berisi kegiatan sosial kemasyarakatan, sosial keagamaan sampai religiusitas hidup terdisplay tepat pada jam kegatan dilakukan. Mirisnya ibadah yang unsur nilainya adalah keikhlasan tanpa motif riya dan sombong menjadi terkaburkan dengan berbagai alasan masuk akal, yaitu amar makruf. Eksistensi ibadah menjadi terpapar jelas dan orang lain mengetahui apa yang sudah dilakukan pengirim dan ibadah model apa yang selalu dilaksanakan. Akhirnya postingan tersebut menimbulkan multitafsir bagi penerima pesan di WAG tersebut.

\section{Teori Ikhlas Beribadah di Era Revolusi Industri}

Ibadah dalam Islam mencakup seluruh anggota tubuh manusia. Beribadah kepada Allah mencakup lisannya, badannya, akalnya hatinya dan seluruh panca inderanya. Lisannya yang berdzikir, badannya yang bergerak shalat, puasa dan jihad, hati yang penuh rasa takut, harap, dan tawakal, dengan akalnya yang berfikir dan bertadabbur, dan dengan panca inderanya yang digunakan dalam ketaatan kepada Allah. Dengan 
Lutifiyah

demikian, ibadah kepada Allah adalah tunduk dan patuh dalam melaksanakan perintah dan menjauhi segala larangan-Nya. Ibadah merupakan istilah perilaku yang sukai di ridhai oleh Allah SWT, berbentuk aqwal atau af al tersembunyi (bissir) atau tampak (alaniyyah). Mengapa kita harus beribadah? Secara falsafati otak mengajak untuk berfikir bahkan menuju kepada berfikir secara radikal (sedalam-dalamnya) dalam memaknai ibadah.

Dalam bahasa Arab Ibadah terambil dari kata abada- ya’budu yang bermakna menyembah/beribadah (Al-Habsyiy, 1997, hal. 886). Ibadah didefinisikn sebagai: nama yang mencakup segala sesuatu yang dicintai oleh Allah dan diridhai-Nya dari perkataan dan perbuatan, baik yang nampak atau tersembunyi (Ibnu Taimiyah, 1979, hal. 4). Ibadah menurut etimologi adalah patuh, pasrah. Ubudiyah artinya tunduk dan merendahkan diri. Secara etimologis ibadah diambil dari kata 'Abid, berarti hamba atau budak dengan keadaan tidak memiliki apapun dan harta yang ada pada dirinya adalah milik majikannya, sehingga semua aktifitas hidup seorang budak atau hamba hanya untuk mendapatkan keridhaan dari majikannya dan menghindarkan diri dari amarahNya. Menurut Syeh Muhammad Abduh tujuan ibadah dalam agama adalah mengingatkan manusia tentang rasa keagungan akan kekuasaan Tuhan yang Maha Tinggi (Syah, 1992, hal. 182). Tujuan ibadah adalah untuk mencapai kepada tauhid sehingga harus memahami konsep ibadah dengan sebenar-benarnya. Dalam surah al-Baqarah ayat 21 disebutkan bahwa tujuan ibadah adalah taqwa kepada Allah SWT, yaitu,

"Hai manusia, sembahlah Tuhanmu yang telah menjadikan kamu dan orangorang sebelum kamu agar kamu bertaqwa."

Kata tattaqun merupakan turunan kata dari waqo, yang mempunyai makna takut atau pemeliharaan diri. Makna taqwa adalah memelihara menjauhkan (memelihara) diri dari siksaan Allah dengan cara melaksanakan segala bentuk perintah-Nya dan diimbangi dengan menjauhi segala bentuk larangan-Nya. Dan dengan beribadah dengan tekun kita akan mencapai suatu derajat takwa kepada Allah Swt. sebagai Tuhan satu-satunya yang Maha Pemelihara dan menciptakan manusia (D. A. Ghazali \& Gunawan, 2015, hal. 187). Dalam kehidupan sehari-hari seringkali mendengar kara ikhlas yang dihubungkan dengan perbuatan amaliyah yang menunjukkan adanya keikhlasan dan ketulusan dalam melakukan perbuatan tersebut. Ikhlas berasal dari Bahasa Arab khalasha (Bahasa Arab) 
yang berarti murni. Ikhlas dalam konteks penelitian ini dimaknai sebagai niat yang murni semata-mata mengharap penerimaan dari Tuhan dalam melakukan suatu perbuatan, tanpa menyekutukan Tuhan dengan yang lain (Qalami, 2003). Menurut Poerwadarminta (1939) dalam konteks Jawa, ikhlas diistilahkan dengan eklas, yang bermakna nriman, kanthi lega lila terusing batin. Padanan kata ikhlas dalam bahasa Inggris adalah sincerity, genuine, dan letting go. Istilah yang disebut terakhir merupakan konsep yang diperkenalkan oleh Corey (2005) yang merujuk pada proses melepaskan segala bentuk perasaan-perasaan negatif yang menyertai suatu peristiwa.

Penjelasan diatas menunjukkan bahwa ikhlas merupakan suatu kondisi di mana seorang Muslim yang ikhlas adalah muslim yang mengorientasikan dirinya hanya kepada Allah dan dijadikan sebagai konsep hidup. Muslim yang sudah punya orientasi hidup dan konsep hidup tidak lagi merasakan ketergantungan dan kebutuhan terhadap kebutuhankebutuhan dasar sebagai manusia. Individu yang berhasil mencapai tingkat tertinggi dalam hierarkhi kebutuhan adalah individu yang memiliki aktualisasi diri. Individu ini memiliki beberapa karakteristik penting, salah satunya adalah otonomi atau selfdirected (Chizanah, 2011b). Dalam berbagai bentuknya khalasa ditemukan dalam 31 kali dengan jumlah 14 kalimat yang berbeda (Khidir, 2005, hal. 6). Secara etimologis kata khalasa dalam bahasa arab mempunyai beberapa pengertian dan makna diantaranya adalah:

1. An-Najaah min asy-syarri wa as-salamah minhu ba'd al-wuqu'fihi. Artinya, selamat dari kejelekan/keburukan setelah mengalaminya

2. min ad-danas wa ar-rijs, yang berarti jernih dari kotoran dan pekerjaan keji (AlFayumi, n.d., hal. 177).

Ikhlas adalah penanggalan al-Haqq dalam mengarahkan semua orientasi dan aplikasi ketaatan. Dengan ketaatan seorang Muslim bermaksud untuk mendekatkan diri pada Allah semata, bukan kepada yang lain, tanpa dibuat-buat, tanpa ditunjukkan untuk sesama makhluk, tidak untuk mencari mendapatkan ujian manusia atau makna-makna lain selain mendekatkan diri pada Allah. Ikhlas juga bisa bermakna penjernihan perbuatan dari campuran semua makhluk atau pemeliharan sikap dari pengaruhpengaruh pribadi (Shofaussamawati, 2013). 
Abu 'Ali Fudhail bin 'Iyadh berkata bahwa: "Meninggalkan amal karena manusia adalah riya'. Dan beramal karena manusia adalah syirik, sedangkan ikhlas adalah, apabila Allah menyelamatkan kamu dari keduanya” (Al-Jauziyah, n.d., hal. 95-96; Al-Nawawi, n.d., hal. 16-17). Dalam kitab tafsirnya, Ibnu Katsir berkata "Inilah dua landasan amalan yang diterima, ikhlas karena Allah dan sesuai dengan Sunnah Rasulullah Shallallahu 'alaihi wa sallam " (Ibnu Katsir \& Umar, n.d., hal. 120-121). Dari maqalah-maqalah diatas jelas bahwa menata hati dalam hal beribadah bukan perkara mudah. Menurut Makki (2008) ikhlas mempunyai lima aspek, yaitu (1) ikhlas dalam arti pemurnian agama; (2) ikhlas dalam arti pemurnian agama dari hawa nafsu dan perilaku menyimpang; (3) ikhlas dalam arti pemurnian amal dari bermacam-macam penyakit dan noda yang tersembunyi; (4) ikhlas dalam arti pemurnian ucapan dari kata-kata yang tidak berguna, kata-kata buruk, dan kata-kata bualan, serta (5) ikhlas dalam arti pemurnian budi pekerti dengan mengikuti apa yang dikehendaki oleh Tuhan. Sebagai hamba yang ikhlas, seorang Muslim harus mengakui kekurangan, kelemahan dan tidak pantas mempunyai rasa lebih dari pada manusia lain. Konsep ikhlas ini menurut Chizanah (2011a) akan membentuk sebuah konsep yang disebut konsep diri. Sebagai abdun muslimun, harus mengakui kelemahan diri, mengakui adanya tugas mengabdi, serta merasa tidak pantas untuk memiliki perasaan superior (superiority feeling) baik dalam level intrapersonal (diistilahkan dengan ujub) maupun sosial (diistilahkan dengan riya',).

Perasaan excellent dikategorikan sebagai elemen perusak ikhlas. Wild desire atau unsur bawaan manusia dan binatang sudah seharusnya dikelola dengan baik sehingga tidak mengaburkan motif-motif transendental yang menyebabkan bercampur dengan motif-motif non-transendental seperti motif mendapatkan materi atau motif mendapatkan popularitas meskipun sekedar memenuhi standar internal. Bila motif yang melandasi suatu perbuatan telah mengalami percampuran, maka akan ada mekanisme perimbangan motif. Mekanisme perimbangan motif merupakan sebuah proses evaluasi untuk menguat-lemahkan motif tertentu, motif yang pada akhirnya dominan itulah yang menjadi motif utama. Bila motif transendental yang dominan, maka mencapai ikhlas, akan tetapi bila motif lain yang dominan maka ikhlas tidak tercapai. Menurut Jamal alDin al-Qasimi riya adalah mencari derajat dan pangkat dalam beribadah sehingga dikategorikan sebagai perbuatan haram. Banyak sekali ayat al-Qur'an dan Hadits yang 
melarang perbuatan riya, karena betapa bahayanya perbuatan tersebut. Diantara ayat yang mudah untuk menunjukkan bahayanya sifat riya adalah Surah al-Maun ayat $4-5$, yaitu:

"Maka kecelakaanlah bagi orang-orang yang shalat, (yaitu) orang-orang yang lalai dari shalatnya"

Karena bahayanya riya, ada seorang shahabat nabi yang bertanya apakah syirik kecil itu, nabi menjawab syirik kecil adalah riya, dimana Allah SWT bersabda bahwa jika pada hari qiyamat nanti ada hamba yang datang dengan seluruh amalnya maka hamba tersebut disuruh untuk melihat apa yang sudah di pamerkan didunia, maka akan dilihat apa yang didapatinya. Hadits ini dipertegas oleh Rasulullah bahwa Allah tidak menerima amalan ibadah meskipun sekecil Dzarrah. Hadits tersebut juga dipertegas bahwa sebaikbaik amal adalah amal yang rahasia dibanding dengan amal yang terbuka dengan pahala 70 kali lipat (Al-Qosimi, n.d.; A. H. I. M. Al Ghazali, n.d., hal. 286).

\section{Metode}

Jenis penelitian ini adalah penelitian kualitatif deskriptif dengan pendekatan study kasus. Penelitian ini secara kontekstual menjadikan manusia sebagai instrumen, dan disesuaikan dengan situasi yang wajar dalam kaitannya dengan pengumpulan data yang pada umumnya bersifat kualitatif. Menurut Bogdan dan Tylor (Moleong, 2007, hal. 3) penelitian metode kualitatif merupakan prosedur meneliti yang menghasilkan data deskriptif berupa kata-kata tertulis atau lisan dari orang-orang dan perilaku yang dapat diamati. Metode pengambilan data dilakukan dengan cara wawancara tertutup dengan mengajukan pertanyaan

Penelitian ini timbul berawal dari maraknya posting-posting ibadah mahdhah yang dilakukan oleh banyak pihak. Misalnya posting ibadah qiyam al-lail pada sepertiga malam, posting pengajian, mengisi acara keagamaan, menjadi muballigh atau muballighah. Sebagai dosen Pendidikan Agama Islam, peneliti tertarik untuk meneliti fenomena ini sehingga sebagai langkah awal peneliti meneliti para dosen Pendidikan Agama Islam yang notabenenya mengajar mata kuliah Pendidikan Agama, Religius dan pemakai Smartphone. Peneliti menggunakan metode wawancara secara tertutup dengan menggunkan lembar pertanyaan agar jawaban lebih terarah. Peneliti lebih mudah 
Lutifiyah

melakukan wawancara karena semua dosen berada pada satu ruangan. Peneliti meneliti 18 Dosen Pendidikan Agama Islam Fakultas Ilmu Tarbiyah dan Keguruan UIN Walisongo. 18 dosen ini merupakan dosen PNS yang sudah bersertifikasi, aktif pengabdian masyarakat dalam bentuk sebagai imam masjid, khatib dan muballigh, serta aktif dalam WAG baik di tingkat fakultas maupun Universitas.

\section{Penggunaan Smartphone di UIN Walisongo}

Smartphone saat ini sudah menjadi benda yang tidak bisa terpisahkan dari pemiliknya. Hal ini terbukti dengan fungsi smarhphone yang tidak hanya untuk menunjang produktifitas kerja, tidak hanya sekedar sebagai telepon genggam, tapi menjadi 'teman' hidup yang paling dibutuhkan. Pergeseran interaksi dan komunikasi penggunaan ponsel yang mengalami perubahan yang signifikan ini membuat smartphone menjadi barang yang selalu dibawa kemanapun pemilik beraktifitas, baik ruang publik ataupun ruang pribadi bahkan menjadi teman sejati. Penelitian ini subyeknya adalah 18 Dosen Pendidikan Agama Islam. Hasilnya adalah pertama, Dosen PAI dengan profesi sebagai muballigh dan pemuka agama sebesar $50 \%$. Kedua, Dosen PAI tidak begitu aktif menggunakan smartphone, $28 \%$. Ketiga, Dosen PAI aktif menggunkan smartphone $67 \%$. Keempat, mengupload kegiatan ibadah menganggap boleh hanya $6 \%$. Kelima, Mengupload kegiatan ibadah tidak boleh $6 \%$. Keenam, Abstain $88 \%$. Ketujuh, Smartphone hanya berfungsi untuk ponsel semata $22 \%$. Kedepalan, Hanya menyimak info dari smartphone $28 \%$. Jika diuraikan, maka hasil dari wawancara tertutup tersebut adalah ada 50 persen yang menjadi muballigh dan pemuka agama (tokoh masyarakat) selebihnya adalah figur biasa dalam masyarakat. Berdasarkan prosentase diatas, dari Dari 18 orang dosen, 5 orang dosen jarang memanfaatkan smartphone, 12 orang aktif menggunakan smartphone. Dosen yang memperbolehkan upload kegiatan ibadah hanya 1 orang dengan alasan mubah, dosen yang tidak memperbolehkan upload kegiatan 1 orang dengan alasan akan menimbulkan ujub dan riya (mendekati haram), dan yang tidak berkomentar sebanyak 16 orang dosen. 


\section{Pembahasan}

Smartphone meninggalkan dampak positif dan negatif bagi usernya. Dengan smartphone segala urusan yang terkesan lambat bisa menjadi lebih cepat, urusan yang tekesan susah bisa menjadi lebih mudah, yang berjarak jauh bisa menjadi lebih dekat, yang berjarak dekat seolah berada didepan mata dengan sekali "klik". Pada umumnya pengguna smartphone hanya ingin sekedar mencari teman tetapi berlanjut memanfaatkan fungsi "teman dekat" nya untuk menyampaikan pesan-pesan pribadinya tanpa menyaring mana yang secret, mana yang public. Penelitian sebelumnya, Sholiha, F \& Fauzi, K.M. (2009) yang berjudul Panduan Ibadah Haji dan Umroh Berbasis Ponsel, menjelaskan fungsi Ponsel (smartphone) sebagai penyedia aplikasi berbasis ponsel. Tujuan dari pembuatan aplikasi ini adalah untuk memudahkan calon jamaah haji di dalam menjalankan ibadah haji dan umroh sesuai dengan syariat Islam. Dengan aplikasi ini diharapkan dapat mempermudah dan mengingatkan jamaah haji dalam melakukan proses ibadah haji dan umroh. Amiral, M (2010) menghasilkan penelitian dengan judul Aplikasi Pengingat Shalat dan Arah Kiblat menggunakan Global Positioning System (GPS) berbasis Android 1.6. Aplikasi ini berisi tentang pengingat shalat dan arah kiblat dengan memanfaatkan global positioning sistem (GPS) pada smartphone android 1.6 tanpa ada tuntunan atau tata cara menjalankan ibadah sholat.

Sekelumit contoh di atas menunjukkan bahwa manfaat atau mafsadat dari smartphone tergantung pada tangan pemegangnya, positif dan negatifnya tergantung yang melihatnya, tidak ada yang bisa membayangkan bahwa smartphone bisa mengubah dunia. Secara ekstrim kita bisa melihat bagaimana sosial media seperti Facebook, Twitter, YouTube, dan teman-temannya telah membantu memicu merubah pola pandang masyarakat global. kita bisa mengetahui semua informasi dalam satu genggaman. Dari satu barang" istimewa" ini setiap orang bisa berbagi informasi penting, bahkan telah mengubah cara berinteraksi, berpikir, membentuk pertemanan, dan mengakses informasi. Setiap orang bebas mengatakan apapun yang mereka inginkan, Dalam hitungan detik, sesuatu yang diucapkan bisa muncul di WhattApp, Facebook, dan diteruskan berulang kali hingga mencapai seluruh penghuni dunia maya, ini salah satu "buah manis" dari smartphone dalam konstelasi global. Mengunduh "buah manis" selanjutnya dari smartphone dalam tataran agama adalah terdisplaynya kegiatan ibadah 
madhdah pengguna dan dikirimkan pada pengguna smartphone lainnya. Kemudahan smartphone benar-benar melenakan karena hampir semua umat Islam memiliki smartphone sebagai teman setia dalam setiap gerak aktifitas. Media sosial yang satu ini seakan tidak pernah melewatkan sedikitpun untuk mengabadikan momen menarik dalam aktivitas sehari-hari. Moment demi moment di bagikan kepada orang lain di WAG, Facebook, dan lainnya, sehingga orang lain menjadi mengetahui setiap detik, menit dan jam dari segala aktifitas "keren" yang sedang dilakukan.

Salah satu efek negatif over posting di smartphone adalah banyak orang yang lupa bagaimana cara bersosialisai, Di tengah revolusi yang disebabkan oleh media sosial, bagi umat Muslim yang berada dalam lingkaran keyakinan terhadap nilai ikhlas beribadah, menjadi gamang menyebabkan kebingungan, kegelisahan, dan keraguan. Orang yang over posting di media sosial menunjukkan betapa sering orang tersebut mengakses media sosial. Orang seperti ini bisa ditengarai sebagai orang yang kecanduan media sosial yang bisa mengganggu kehidupan sehari-hari, parahnya lagi menjadi stalker maniac. efek negatif yang lain adalah semakin hilangannya jadi diri dalam kehidupan nyata akibat sering berjibaku dengan dunia maya. Tanpa disadari, bahaya over posting di media sosial adalah kehilangan privasi karena semua aktifitas telah didisplay tanpa sensor. Lalu bagaimana jika yang diposting adalah kegiatan ibadah yang seyogyanya dilaksanakan secara apik, khusuk dan tanpa pamrih justru terdisplay di media sosial sebagai wujud ke"eksis"an pengguna. Apakah hal ini akan mencerabut makna ruhiyah ibadah yang seharusnya sepi dari pamrih menjadi ramai dengan ajungan jempol tanda like.

Secara khusus, ibadah adalah sebuah rutinitas yang memiliki sistem tertentu yang berupa syarat dan rukun yang dilaksanakan secara formal dan dibatasi oleh ketentuanketentuan hukum yang berlaku untuk masing-masing personal (fardhu'ain) maupun perwakilan dalam sebuah komunitas tertentu (fardhu kifayah). Beribadah dalam makna luas mengandung unsur pengakuan terhadap kerendahan diri di hadapan Allah, menundukkan keangkuhan diri, menyadari keterbatasan, mengakui semua bentuk kekurangan dengan pengakuan yang sejujurnya, seikhlasnya, lalu pasrah secara total melaksanakan apa yang menjadi titah-Nya. Dalam pandangan Islam, hanya Allah yang berhak menerima dan menilai. Indahnya Islam, seluruh aktivitas kehidupan sehari-hari dapat dihitung sebagai ibadah. Setiap suara hati, ucapan, dan perbuatan dapat dipandang 
sebagai ibadah apabila didasari dengan niat. Niat sangat menentukan sekali apakah ibadah itu mardud atau maqbul, berbalas pahala (surga) ataukah berbalas dosa (siksa neraka).

Untuk bisa memperoleh keindahan ibadah, orang Muslim harus tahu bagaimana tata cara agar beribadah bisa mencapai tujuan. Jawabanya adalah seorang Abid harus mempunyai ilmu pengetahuan tentang ibadah. Ilmu pengetahuan tentang ibadah sangat diperlukan untuk mencapai kesempurnaan ibadah sehingga dapat maqbul dan terhindar dari perbuatan ibadah tanpa makna. Ilmu pertama yang harus diketahui adalah pertama, Niat, merencanakan ibadah sebagai pijakan awal. Niat ada didalam hati, sedangkan yang diucapkan adalah lafadznya niat. Karena niat ada didalam hati, maka hanya Allah yang tahu. Niat yang diterima oleh Allah adalah niat yang ikhlas (bersih dari noda/kepentingan selain Allah), tidak berharap puji orang lain, tidak khawatir dicerca, tidak pernah berharap imbal balik dari siapapun selain Allah. Keikhlasan memiliki peranan strategis sebagai upaya mencapai tingkatan yang tinggi di sisi Allah. Tingkatan ikhlas itupun memiliki perbedaan sebagaimana keimanan juga memiliki tingkatan yang berbeda. Menurut para ulama', ikhlas terbagi menjadi dua bagian, yaitu; ikhlas dalam beramal dan ikhlas demi pahala. ikhlas dalam beramal adalah keinginan untuk mendekatkan diri kapada Allah, sedangkan ikhlas demi pahala adalah keinginan untuk mendapatkan ganjaran pahala (Al-Ghazali, 2002, hal. 119). Konsep diri sebagai hamba Tuhan merupakan aspek terpenting dalam ikhlas yang menunjukkan bahwa ikhlas merupakan konstruk yang bernuansa spiritual. Spiritualitas sendiri memiliki peranan penting dalam pengembangan kesehatan mental (Cotton, S., Larkin, Hoopes, A., Cromer, \& Rosenthal, 2005; Cotton, S., Zebracki \& Rosenthal, S.L., Tsevat, J., Drotar, 2006).

Kedua, perbuatan manusia dinilai dari niatnya terlebih dahulu. Apabila beramal niat ikhlas hanya karena Allah SWT semata tanpa ada hal lain yang menyelimuti hatinya termasuk keruhnya niat karena ingin dipuji, niat ibadah untuk mendapatkan harta, pangkat, dan kedudukan. Jika niatnya sudah berbeda maka yang ada hanyalah kehancuran. Ketiga, ikhlas merupakan niat sepenuh hati menjalankan ibadah karena Allah SWT. Sebagai laku spiritualitas maka dalam setiap laku ibadah harus memurnikan niat, bahwa tidak ada makhluk lain yang dapat disembah selain Allah. Menyembah Allah harus dijauhkan dari sifat riya "e yang meginginkan pujian dari orang lain, atau ingin 
dilihat orang lain. Keempat, tawakkal merupakan sebuah sikap seorang abid yang menyadari keterbatasan dirinya sehingga tidak mampu menyelesaikan amanat Allah dengan sempurna. Tawakal terlahir setelah adanya usaha dalam pelaksanaan ibadah dalam pelaksanaan rukun, syarat dan sunnahnya sehingga seorang hamba harus tetap memasrahkan seluruh kekuatannya agar tidak timbul rasa angkuh, bangga diri, sombong dan puas diri yang dapat menghancur leburkan nilai kebaikan ibadahnya. Dari uraian diatas ditemukan benang merah yaitu sistem ibadah mahdhah, ilmu/tata cara beribadah, niat, pasrah, revolusi industry.

Ibadah mahdhah mempunyai aturan ketat dalam pelaksanaannya, misalnya tata cara ibadahnya harus berpola pada tuntunan al-Qur'an dan Sunah, berdasarkan pada uswah dari Rasulullah dan bersifat suprarasional karena ibadahnya kadang dianggap tidak masuk akal. Ibadah ini memerlukan konsentrasi tinggi, ketundukan, kepasrahan dan kepatuhan luar biasa sehingga terasa aneh jika orang yang sedang shalat, dzikir dan ibadah mahdhah lainnya, mengambil gambar kemudian mengirimkannya, bersamaan atau setelah ritual dilaksanakan. Hal ini yang menyebabkan seorang abid harus mempunyai ilmu dasar bagaimana seharusnya layaknya seorang yang sedang berkomunikasi, orang yang sedang bersendagurau, orang yang sedang mengeluh, bahkan orang yang sedang meminta, ber-etika kepada lawan bicaranya. Ibadah tidak bisa lepas dari sebuah niat yang sangat dibutuhkan dalam setiap kegiatan karena setiap perbuatan itu tergantung dari niatnya dan hasilnya berbanding lurus dengan niatnya. Jika berniat untuk tafakur kepada gusti Allah maka sudah selayaknya kita merasa asor, rendah, tidak membutuhkan kritik orang lain, alem dari orang lain atau like dari orang lain. Ranah privat seperti ini tidak harus tergerus oleh budaya global yang sekarang sedang marak. Jangan takut dikatakan bukan ahli ibadah, bukan ahli surga atau tidak terkenal di masyarakat karena landasan ibadah mahdzah bukan untuk ikut meramaikan revelusi industri, tapi lebih dari ini yaitu menghiasi para pelaku revolusi industri, agar setiap gerak nadi kerja di balur dengan nuansa ke-Tuhanan, sehingga tidak hanya motif duniawi semata tapi juga motif ukhrowi.

Titik tekan dalam penulisan tema ini adalah bagaimana jika ibadah di unggah kemanapun semau yang punya smartphone, layakkah hal ini dilakukan oleh seorang ahli ibadah yang ingin ibadah dan dekat dengan Tuhannya. Misalnya ketika seseorang sedang 
shalat malam, dzikir atau pengajian, mengupload dirinya sendiri di sosial media melalui smartphone sehingga orang lain tahu setiap detil kegiatan ibadahnya. Hal ini menunjukkan menunjukkan bahwa manfaat dan tidak manfaaat, berfungsi atau tidak berfungsinya smarthphone tergantung dari siapa yang menjadi "tuan" bagi smartphonne. Smarhphone ditangan para ahli akan menjadi benda "emas" yang temuannya siap dipublikasikan ke khalayak umum, smartphone ditangan para penggila gaya, maka yang tersedia hanya foto pribadi, foto kenangan atau foto refreshing yang siap untuk dibagikan kepada grupnya.

Bagi hamba yang sudah Taqarrub kepada Allah, ibadah akan disimpan diri sendiri sebagai pengalaman yang indah. Dekat dengan Allah untuk memperbaiki kualitas diri dan hamba yang membiasakan diri dekat dengan Allah tidak akan memperdulikan apakah akan dipuji orang lain, dilihat orang lain atau bahkan dipermalukan orang lain. Bagi seorang Abid hanya Allah yang pantas menilai apapun yang dilakukan. Orang yang dekat dengan Allah tidak mudah mengagumi suatu hal yang akan binasa dikemudian hari. Ia hanya kagum kepada Allah, kagum akan ciptaan-Nya, kekuasaan-Nya, dan kagum akan kedahsyatan anugerah-Nya. Seorang hamba Allah yang dekat dengan Allah akan senantiasa ikhlas dalam mengerjakan amal dan ibadah. Karena baginya, Allah lah yang patut untuk dijadikan tujuan. Ibadahnya, perilakunya, hidup dan matinya hanya milik Allah semata. Setan akan selalu menggoda manusia yang semakin taat kepada-Nya.

\section{Simpulan}

Kehidupan modern ini seolah mensyahkan setiap kegiatan syahdu komunikasi hamba dengan Tuhannya menjadi konsumsi publik. Tradisi keikhlasan salafy menjadi dipertanyakan, kemurnian hati diperdebatkan. Qiblat ibadah hanya kepada Allah berputar (atau mungkin berbalik 180 derajad) pada qiblat makhluk fana yang tiada abadi. Ucapan like sangat diminati, bahkan memaksa diri untuk "mengajak" kepada sesama makhluk untuk ikut turut serta meramaikan dan membahanakan setiap hening kesucian hati. Hasil dari penelitian ini menunjukkan bahwa dosen di jurusan Pendidikan Agama Islam di Universitas Islam Negeri Semarang aktif menggunakan smartphone tapi tidak memperhatikan konten posting ibadah mahdhah dengan bukti lebih banyak yang abstain. Sudah selayaknya seorang Muslim melaksanakan ibadah mahdhah dengan mengetahui 
etika dan pola ibadahnya sehingga mengantarkan seorang abid menjadi Muslim yang ikhlas. Keikhlasan beribadah tidak lepas dari niat, niat beribadah sebagai bentuk kepasrahan seorang hamba kepada majikannya tanpa berfikir apakah akan berupah pahala atau tidak. Perubahan era globalisasi tidak akan mampu menggantikan kekhusukan seorang hamba yang ikhlas hanya dengan mandi pujian atau riuh tapuk tangan. 


\section{Referensi}

Al-Fayumi, A. ibn M. ibn A. A.-M. (n.d.). al-Misbah al-Munir fi Gharib al-Syarkhi alKabir. Beirut: Al-Maktabah Al-Ilmiyyah.

Al-Ghazali. (2002). Mihrab kaum Arifin-Apresiasi Sufistik Para Salikin. Surabaya: Pustaka Progresif.

Al-Habsyiy, H. (1997). Kamus al-Kausar: Arab-Indonesia, Darussaggaf, Surabaya Munawwir A.W., 1997, Kamus al-Munawwir Arab-Indonesia Terlengkap. Surabaya: Pustaka Progessif.

Al-Jauziyah, I. Q. (n.d.). Madarijus Salikin. Kairo: Darul Hadtis.

Al-Nawawi. (n.d.). Al Majmu’ Syarhul Muhadzdzab. Beirut: Darul Fikr.

Al-Qosimi, S. M. J. al-D. al-Q. (n.d.). Mauidhah lil Mukmunin min Ihya ulum al-Din. Beirut: Dar al Fikr.

Al Ghazali, A. H. I. M. (n.d.). Ihya’ Ulum al-Din. Libanon: Dar al Kutub al Islamiyah.

Amiral, M. (2010). Aplikasi Pengingat Shalat dan Arah Kiblat menggunakan Global Positioning Sistem (GPS) berbasis Android 1.6. Program Studi Teknik Informatika: STMIK GI MDP.

Chizanah, L. (2011a). Konstruk Psikologi Ikhlas (Sebuah Kajian Hermeneutika). International Conference and The 3rd of Congress of API Proceedings.

Chizanah, L. (2011b). Validitas Konstruk Ikhlas: Analisis Faktor Eksploratori terhadap Instrumen Skala Ikhlas, Jurnal Psikologi. Jurnal Psikologi, 38(2).

Corey, G. (2005). Theory and Practice of Counseling and Psychotherapy 7th Edition. Belmont: Brooks/Cole-Thompson Learning.

Cotton, S., Larkin, E., Hoopes, A., Cromer, B. A., \& Rosenthal, S. L. (2005). The impact of adolescent spirituality on depressive symptoms and health risk behaviors. Journal of Adolescent Health, 36(1).

Cotton, S., Zebracki, K., \& Rosenthal, S.L., Tsevat, J., Drotar, D. (2006).

Religion/spirituality and adolescent health outcomes: a review. Journal of Adolescent Health, 38(1).

Ghazali, D. A., \& Gunawan, H. (2015). Studi Islam Suatu Pengantar Dengan Pendekatan Interdisipliner. Bandung: PT Remaja Rosdakarya.

Ibnu Katsir, A. al-I. I. al-D., \& Umar, A. al-F. I. ibn. (n.d.). Tafsir Ibnu Katsir. Riyadh: Maktabah Darus Salam. 
Ibnu Taimiyah, A. A. al-H. (1979). Al-Ubudiyah. Jeddah: Dar al-Mudun.

Jocom, N. (2013). Peran Smartphone Dalam Menunjang Kinerja Karyawan Bank Prismadana (Studi Pada Karyawan Bank Prismadana Cabang Airmadidi). Journal "Acta Diurna," 1(1).

Khidir, M. Z. M. (2005). Mu'jam Kalimat Al-Quran Al-Karim.

Makki, A. T. (2008). The Secret of Ikhlas ('Ilm al-Qulub). Jakarta: PT Serambi Ilmu Semesta.

Moleong, L. J. (2007). Metodologi Penelitian Kualitatif. Bandung: PT. Remaja Rosda Karya.

Poerwadarminta, W. J. S. (1939). Baoesastra Djawa. Batavia: B. Wolters' UitgeversMaatschappij.

Qalami, A. . (2003). Ringkasan Ihya' Ulumiddin. Surabaya: Gitamedia Press.

Shofaussamawati. (2013). Ikhlas Perspektif al-Qur'an: Kajian Tafsir Maudhu'i. Hermeunetik, 7(2).

Sholiha, F., \& Fauzi, K. . (2009). Panduan Ibadah Haji dan Umroh Berbasis Ponsel. Program Studi Teknik Informatika, STMIK GI MDP.

Syah, I. M. (1992). Filsafat hukum Islam. Jakarta: Bumi Aksara. 